\title{
Assembly and analysis of a male sterile rubber tree mitochondrial genome reveals DNA rearrangement events and a novel transcript
}

\author{
Jeremy R Shearman', Duangjai Sangsrakru', Panthita Ruang-areerate', Chutima Sonthirod', \\ Pichahpuk Uthaipaisanwong ${ }^{1}$, Thippawan Yoocha' ${ }^{1}$ Supannee Poopear ${ }^{1}$, Kanikar Theerawattanasuk², \\ Somvong Tragoonrung ${ }^{1}$ and Sithichoke Tangphatsornruang ${ }^{1 *}$
}

\begin{abstract}
Background: The rubber tree, Hevea brasiliensis, is an important plant species that is commercially grown to produce latex rubber in many countries. The rubber tree variety BPM 24 exhibits cytoplasmic male sterility, inherited from the variety GT 1.

Results: We constructed the rubber tree mitochondrial genome of a cytoplasmic male sterile variety, BPM 24, using 454 sequencing, including $8 \mathrm{~kb}$ paired-end libraries, plus Illumina paired-end sequencing. We annotated this mitochondrial genome with the aid of Illumina RNA-seq data and performed comparative analysis. We then compared the sequence of BPM 24 to the contigs of the published rubber tree, variety RRIM 600, and identified a rearrangement that is unique to BPM 24 resulting in a novel transcript containing a portion of atp9.

Conclusions: The novel transcript is consistent with changes that cause cytoplasmic male sterility through a slight reduction to ATP production efficiency. The exhaustive nature of the search rules out alternative causes and supports previous findings of novel transcripts causing cytoplasmic male sterility.
\end{abstract}

Keywords: Rubber tree, Hevea brasiliensis, Mitochondria, Cytoplasmic male sterility, Genome sequencing

\section{Background}

Mitochondria are membrane-bounded organelles that function in energy metabolism, biosynthesis of cofactors and vitamins, cellular differentiation, signalling, cell growth, and cell death [1]. They contain their own genomes which are inherited maternally in most plant species. The first flowering plant mitochondrial DNA (mtDNA) to be completely sequenced was Arabidopsis thaliana [2], since then there have only been 37 additional mitochondrial genomes sequenced and analyzed from flowering plants [www. ncbi.nlm.nih.gov/Genomes/]. These additional mitochondrial genomes have increased our understanding of genome rearrangement, DNA transfer and phylogenetic diversity. Plant mitochondrial genomes encode tRNAs, rRNAs, proteins and ribosomal proteins and range in size from $200 \mathrm{~Kb}$

\footnotetext{
* Correspondence: sithichoke.tan@biotec.or.th

'National Center for Genetic Engineering and Biotechnology, 113 Thailand Science Park, Paholyothin Road, Khlong Nueng, Khlong Luang, Pathumthani 12120, Thailand

Full list of author information is available at the end of the article
}

in Brassica hirta [3] to 2.74 $\mathrm{Mb}$ in Cucumis melo [4]. Mitochondrial genome expansion in land plants is primarily due to large intergenic regions, repeated segments, intron expansion and incorporation of foreign DNA such as plastid and nuclear DNA $[5,6]$. Accumulation of repetitive sequences in plant mitochondrial genomes cause frequent recombination events and dynamic genome rearrangements within a species $[7,8]$. Several mutations by gene rearrangement of the mitochondrial genes were found associated with cytoplasmic male sterility (CMS) such as the T-urf13 gene in maize [9], pcf gene (a fusion of atp9 and $\operatorname{cox} 2$ portions) in petunia [10], $\operatorname{cox} 1$ in rice [11] and mutations in ATPase subunits in sunflower [12] and Brassica [13]. RNA processing also plays an important role in controlling CMS as evidenced in orf355/orf77 (atp9) and T-urf13 in maize $[14,15]$.

Conventional strategies for obtaining mitochondrial genome sequencing involve isolation of mitochondrial DNA, cloning and sequencing. However, problems with this 
approach of mitochondrial genome sequencing include difficulty resolving sequence of the mitochondrial genome from the nuclear genome and assembly of a single circular genome due to the highly dynamic genome structure. Rivarola et al. [16] suggested that examination of the read depths of the resulting assemblies could be used to separate reads of nuclear, chloroplast and mitochondria origin. With the development of next generation sequencing (NGS) technologies, new strategies have been used to obtain plant mitochondrial genomes. A combination approach of shotgun and paired-end NGS sequencing from non-enriched whole genome DNA libraries have been successfully used to obtain the mitochondrial genomes of melon [4], carrot [17] and date palm [18].

Hevea brasiliensis, or rubber tree, is an important economical plant that can produce natural latex at a commercial scale. Sequencing information of its nuclear genome [19], plastid genome [20] and mitochondrial genome is important for genetic improvement and understanding of biological mechanisms of the plant species. The closest plant species to $H$. brasiliensis with a mitochondrial genome draft reported is from Ricinus communis which is in the same Euphorbiaceae family [16]. In this study, we obtained a draft of the rubber tree mitochondrial genome of the variety BPM 24, a cytoplasmic male sterile descendant of a GT 1 (female) × AVROS 1734 (male) cross [21]. The variety GT 1 is male sterile, its offspring BPM 24 is male sterile and the offspring of BPM 24 are also male sterile. Thus the cause for male sterility in this line is cytoplasmically inherited, which makes the mitochondrion the most probable cause. The assembled BPM 24 genome was characterized for gene annotation, transcription analysis, RNA editing events, sequence variation and recombinations within the species that cause cytoplasmic male sterility in rubber tree.

\section{Methods \\ Plant materials}

Shoot apical meristem samples of $H$. brasiliensis (varieties BPM 24, RRII 105, RRIC 110, PB 235, RRIT 251 and RRIM 600) were collected for DNA and RNA extraction from an experimental field at the Rubber Research Institute of Thailand, Ministry of Agriculture and Cooperatives, Thailand. The samples for DNA extraction were processed using the DNeasy Plant Mini Kit (Qiagen, CA, USA). The samples for RNA extraction were immediately frozen in liquid nitrogen and stored at $-80^{\circ} \mathrm{C}$ until RNA extraction following the protocols in Triwitayakorn et al. [22].

\section{Sequence analysis}

The DNA from variety BPM 24 was sequenced in house on a Genome Sequencer (GS) FLX platform (Roche, USA) using two libraries: shotgun sequencing and 8-kb pairedend sequencing according to Roche protocols. In addition this sample was sequenced on a Hiseq 2000 platform (Illumina, USA) using paired-end sequencing at Macrogen (Korea). The genomic sequencing reads from 454 were assembled de novo using gsAssembler (Newbler, version 2.7, Roche, USA). Scaffolds were produced using SSPACE_basic_V2.0 [23]. The scaffold graph was produced using bb.454contignet [17]. The assembled contigs were searched for sequence homology against the publicly available plant mitochondrial genomes and repeats were identified using Reputer. The Illumina data was mapped to the 454 assembled contigs to improve on the assembly and the sequence depth was used to differentiate between mitochondrial sequences and nuclear encoded mitochondrial copies. To identify regions of plastid origin, the assembled sequences were aligned against the rubber tree chloroplast genome [20] using BLAST. Comparison of mitochondrial genome structures of rice, tobacco, castor bean and rubber tree was performed using MAUVE [24].

The extracted RNA from the six rubber tree varieties were sequenced on an Illumina HiSeq2000 at Macrogen (Korea). RNA sequence data quality was checked using FastQC and was cleaned using TRIMMOMATIC v0.27 [25]. The reads were mapped to the assembled genome using TopHat (v2.0.9) [26] with bowtie (v1.0.0) [27] and the fusion search option.

\section{Sequence annotation}

Open Reading Frames (ORFs) were predicted using Open Reading Frame Finder [https://www.ncbi.nlm.nih.gov/gorf/ gorf.html]. The tRNA genes were searched using tRNAscanSE [28]. The annotated genes were also checked with the plant mitochondrial genome annotation program Mitofy [29]. All predicted ORFs, tRNA genes and rRNA genes were searched against the publicly available mitochondrial nucleotide and protein sequence database. Expression of genes was checked by mapping the RNA sequencing data from each sample to the assembled genome using TopHat. RNA-editing events were identified from this mapping data using VarScan (v2.3.4) [30], in addition RNA-editing events were predicted using PREP-Mt [31]. RNA-editing events were compared to other plant species by obtaining sequences from genbank with RNA-editing information and performing an alignment. Trans-membrane domains were predicted using TMHMM (v2.0) [32].

\section{PCR and Sanger confirmation}

The contig graph was confirmed by PCR using 50 primer pairs (see Additional file 1). PCR for rearrangement sites was performed for each of the six varieties of rubber tree in both genomic and cDNA samples. Primers for suspected rearrangement sites were designed so that they flanked the suspected rearrangement site in non repetitive genomic DNA and additional primers were designed 
within the regions indicated as expressed by the RNA-seq mapping data (see Additional file 2).

\section{Phylogenetic tree}

The phylogenetic tree was constructed using seven species (Ricinus communis, Hevea brasiliensis, Carica papaya, Brassica napus, Raphanus sativus, Arabidopsis thaliana and Cycas taitungensis as an outgroup). Gene sequences from each species for 21 conserved genes (nad1, nad2, nad3, nad4, nad4L, nad5, nad6, nad7, nad9, cob, cox1, cox2, cox3, atp1, atp4, atp6, atp8, atp9, rps3, rps4, rps12) were compared and a maximum likelihood tree was constructed using MEGA 5 with 1000 bootstrap replications [33].

\section{Results and discussion}

\section{Mitochondrial sequence assembly}

We assembled the mitochondrial sequence of the rubber tree variety BPM 24 from 454 sequence data into 37 contigs ranging from $101 \mathrm{bp}$ to $147 \mathrm{~kb}$ in length with an N50 size of $51 \mathrm{~kb}$ (DDBJ: AP014526). Additional contigs were identified as mitochondrial sequence but, despite a similar GC content, had a sequence depth less than $10 \%$ of the other contigs. The low sequencing depth indicated that these contigs were nuclear encoded copies of mitochondrial sequence and these sequences were removed from the sequence assembly. Scaffolding the confirmed mitochondrial contigs produced a complex scaffold graph with 37 nodes and 49 edges that consisted of many small loops linked by repeat sequences. Twenty-one of these contigs had single 3 ' and 5' edges, 15 contigs had two 3 ' and/or 5' edges and one contig had three 3' and 5' edges resulting in thousands of possible configurations (see Additional file 1). To obtain the master circle mitochondrial sequence, the contig graph was traversed in such a way as to use all of the contigs at least once. We used Illumina paired-end data to confirm the scaffolds predicted by the 454 data and to correct homopolymer errors that are common in pyrosequencing data. We also performed PCR using a set of primers designed to the edges of each scaffold to confirm that these scaffolds did indeed join as shown by the presence of a PCR product (see Additional file 1). Several large segments of the mitochondrial genome were repeated in reverse orientation in the master circle resulting in duplication of approximately $350 \mathrm{~kb}$ in the master circle (Figure 1).

Several studies have attempted to identify the mechanism of plant mitochondrial DNA replication (for review see [34]) with evidence found for rolling circle replication and recombination mediated replication. However, the exact mechanism remains to be fully elucidated. In addition, studies using pulse field gel electrophoresis and electron microscopy failed to find a single circular strand of DNA, instead finding many smaller subgenomic circles and linear strands of DNA consistent with rolling circle replication products ([35] and references). Recent efforts to sequence plant mitochondrial genomes have also found evidence for subgenomic circles in the form of scaffold graphs of varying complexity [36-42], much like what we found in this study. In fact some studies have suggested that subgenomic circles are the native state of plant mitochondrial genomes [36,40], and must therefore be self replicating. With so many repeat sequences it is quite possible that an origin of replication sequence could exist multiple times in plant mitochondrial genomes allowing for independently replicating subgenomic circles to exist. Furthermore it is difficult to imagine how such diversity in mitochondrial genome size and subgenomic circle number could exist if there was but a single origin of replication with only the complete master circle able to segregate to dividing mitochondria. Such a mechanism would surely result in loss of non essential sequence and evolution towards more compact mitochondrial genomes as observed in mammalian mitochondrial genomes [43]. Thus our data adds to the growing body of evidence that plant mitochondrial genomes can consist of several independently replicating subgenomic circular DNA strands, a single circular DNA strand, or a mixture of both. Despite this, it is common practice to reconstruct a single 'master circle' DNA strand to represent the complete mitochondrial genome $[36,39]$.

Plant mitochondrial genomes contain a large number of repeat sequences that enable homologous recombination to produce multiple subgenomic circles (for review see [44]). The rubber tree contig graph predicts a large number of possible subgenomic circles for the mitochondrial genome, suggesting mitochondrial mosaicism exits in rubber tree. The large number of possible subgenomic circles is facilitated by a large number of direct and inverted repeats. Over 34\% of the mitochondrial genome consists of repeat and inverted repeat motifs. The most common repeat size was $20-40$ bp with over 1800 instances accounting for $3.4 \%$ of the genome, followed by the $41-200 \mathrm{bp}$ size range accounting for $1.16 \%$ of the genome (Table 1 ). Almost $30 \%$ of the genome consists of repeats larger than $200 \mathrm{bp}$, in many cases these large repeats formed individual contigs and are a contributing factor in the complexity of the contig graph (Table 1). Mapping reads from the Illumina paired-end run to the assembly gave a range of read depths that support variation in copy number of loci across the mitochondrial genome, the highest read depth was approximately three fold higher than the lowest depth (see Additional file 3). This suggests that the rubber tree subgenomic circles exist at different stoichiometries, similar to what was found in the cucumber mitochondrial genome [36]. Thus the rubber tree master circle is accurate in terms of sequence and contig orientation, but may under-represent the true copy number of each contig. 


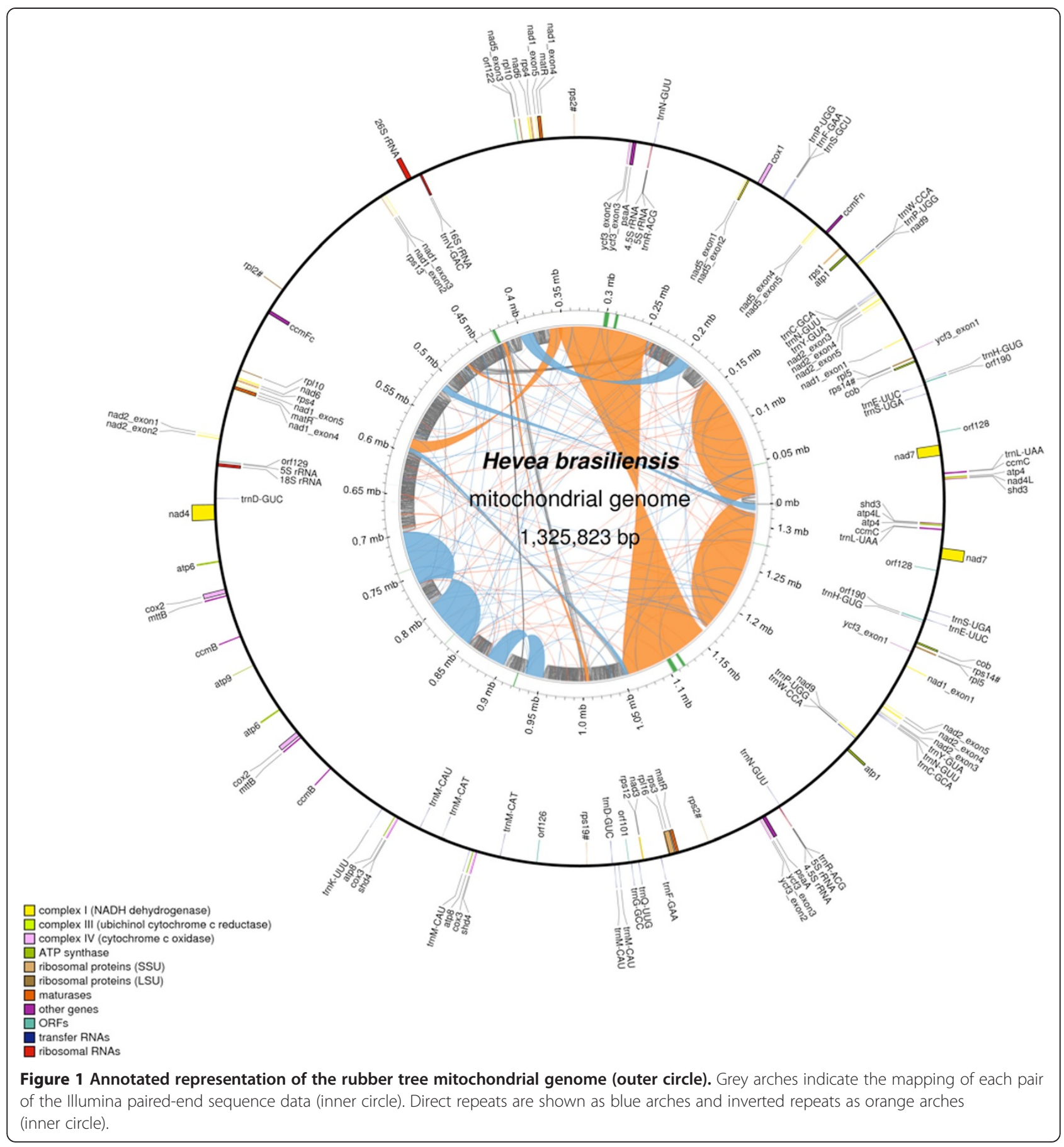

\section{Annotation of the mitochondrial genome}

We identified 65 open reading frames that match known genes (Table 2). These gene annotations were supported by Illumina paired-end RNA-seq data from BPM 24 plus 5 additional clones (RRIM 600, RRIC 110, RRII 105, RRIT 251 and PB 235). These genes were primarily from the oxidative phosphorylation pathway (24 genes) and ribosome (12 genes). Fifty-four genes are encoded by a single exon and 11 genes are encoded across multiple exons. We found trans-splicing in three genes, nad1, nad2 and nad5. Group II trans-splicing in these three nad genes is well documented and occurs in organelles of multiple plant species (for review see [45]). Each of the trans-spliced nad genes have large introns, up to several hundred $\mathrm{kb}$, and at least one exon encoded on the opposite strand compared to the other exons for that gene, consistent with findings in other species [45]. In addition a gene transferred from the chloroplast, $y c f 3$, would require trans-splicing 
Table 1 Size, number and direction of repeat sequences in the rubber tree mitochondrial genome

\begin{tabular}{lllll}
\hline $\begin{array}{l}\text { Repeat } \\
\text { length (bp) }\end{array}$ & $\begin{array}{l}\text { Number of } \\
\text { repeats }\end{array}$ & \% genome size & Direct & Inverted \\
\hline $20-40$ & 1837 & 3.44 & 962 & 875 \\
$41-60$ & 160 & 0.59 & 88 & 72 \\
$61-80$ & 42 & 0.21 & 21 & 21 \\
$81-100$ & 14 & 0.09 & 9 & 5 \\
$101-200$ & 27 & 0.26 & 13 & 14 \\
$>200$ & 29 & 29.95 & 15 & 14 \\
Total & 2109 & 34.55 & 1108 & 1001 \\
\hline
\end{tabular}

Table 2 Coding information of the rubber tree mitochondrial genome

\begin{tabular}{|c|c|}
\hline Gene function & Gene name \\
\hline Complex I & $\begin{array}{l}\text { (2x)nad1[5], (2x)nad2[5], nad3, nad4[4], (2x)nad4L, } \\
\text { nad5[5], (2x)nad6, (2x) nad7[5], (2x)nad9 }\end{array}$ \\
\hline Complex II & $(2 x) \operatorname{shd} 3,(2 x) \operatorname{shd} 4$ \\
\hline Complex III & $(2 x) \operatorname{cob}$ \\
\hline Complex IV & $\operatorname{cox} 1[2],(2 x) \operatorname{cox} 2[2], \operatorname{cox} 3$ \\
\hline Complex V & (2x)atp1, (2x)atp4, (2x)atp6, (2x)atp8, atp9 \\
\hline $\begin{array}{l}\text { Cytochrome-c } \\
\text { biogenesis }\end{array}$ & $(2 x) \mathrm{ccmB},(2 x) \mathrm{ccmC}, \mathrm{ccmFc}[2], \mathrm{ccmFn}$ \\
\hline $\begin{array}{l}\text { SecY-independent } \\
\text { transport }\end{array}$ & $(2 x) m t t B$ \\
\hline Ribosomal RNAs & $5 S$ rRNA, 185 rRNA, 265 rRNA \\
\hline $\begin{array}{l}\text { Ribosomal protein } \\
\text { small subunit }\end{array}$ & rps1, rps3[2], (2x)rps4, rps12, rps13 \\
\hline $\begin{array}{l}\text { Ribusomal protein } \\
\text { large subunit }\end{array}$ & $(2 x) r p / 5,(2 x) r p / 10, r p / 16$ \\
\hline Intron maturase & $(3 x)$ matR \\
\hline $\begin{array}{l}\text { Chloroplast transferred } \\
\text { complete genes }\end{array}$ & $\begin{array}{l}(2 x) 4.55 \text { rRNA, (2x)5S rRNA, } 16 S \text { rRNA, (2x)psaA, } \\
(2 x) y c f 3[3]\end{array}$ \\
\hline $\begin{array}{l}\text { Conserved } \\
\text { Hypothetical genes }\end{array}$ & $\begin{array}{l}\text { orf101, orf122, orf126, (2x)orf128, orf129, (2x) } \\
\text { orf190 }\end{array}$ \\
\hline Transfer RNA & $\begin{array}{l}\text { (2x)trnC-GCA, trnD-GUC, trnD-GUC-cp, (2x)trnE-UUC, } \\
\text { (2x)trnF-GAA, trnG-GCC, (2x)trnH-GUG-cp, trnK-UUU, } \\
\text { (2x)trnL-UAA[2], (4x)trnM-CAU, (2x)trnM-CAU-cp, (4x) } \\
\text { trnN-GUU-cp, trnP-UGG, (2x)trnP-UGG-cp, trnQ-UUG, } \\
\text { (2x)trnR-ACG-cp, trnS-GCT, (2x)trnS-TGA, trnV-GAC-cp, } \\
\text { (2x)trnW-CCA-cp, (2x)trnY-GTA }\end{array}$ \\
\hline Pseudogenes & rpl2, (2x)rps2, (2x)rps 14, rps19 \\
\hline $\begin{array}{l}\mathrm{cp} \text {-derived gene } \\
\text { fragment transfer }\end{array}$ & $\begin{array}{l}16 S \text { rRNA, } 23 S \text { rRNA, atpE, ndhF, }(2 x) p s a B,(2 x) \\
\text { psbC, (2x)rpoA, rps } 12 \text { 3end, }(2 x) y c f 1,(2 x) y c f 15, \\
(2 x) y c f 2, y c f 68\end{array}$ \\
\hline $\begin{array}{l}\text { Lost gene (transferred } \\
\text { to nucleus) }\end{array}$ & rps10[2] \\
\hline
\end{tabular}

*Note: Bracketed numbers indicate copy number of each gene, square brackets indicate number of exons, chloroplast derived tRNAs have -cp appended to them. to produce a functional mRNA in the rubber tree mitochondrion.

There were 19 tRNA genes identified, five of which occurred twice in the assembled mitochondrial master circle (Table 2). Seven of the tRNA genes plus 12 other genes are also found on the rubber tree chloroplast genome suggesting that they have been transferred from the chloroplast to the mitochondrial genome. It is unlikely to be chloroplast DNA contamination as these sequences differ from those in the chloroplast genome at multiple sites and there are sequencing reads extending from mitochondrial sequence to these transferred chloroplast fragments. Gene transfer from chloroplast to mitochondria is a common phenomenon in plants and the chloroplast copies that we found in the rubber tree mitochondria are largely consistent with previously identified chloroplast gene transfer events [46]. Exceptions include two genes, trnSGGA and trnI-CAU, that have been transferred from chloroplast to mitochondria in a range of species but were not found in the rubber tree mitochondrial genome. A third gene, trnE-UUC, also known to have been transferred from chloroplast to mitochondria in other species, was found in the rubber tree mitochondria, but did not appear to be from the chloroplast DNA. Ricinus communis was similar to rubber tree in that it lacked the trnI-CAU gene and had a mitochondrial copy of trnE-UUC that was different to the chloroplast copy, but unlike rubber tree had a chloroplast copy of trnS-GGA. This shows that the chloroplast-derived trnS-GGA was lost to rubber tree after the split from Ricinus and that the either chloroplastderived trnI-CAU and trnE-UUC genes were lost to the Ricinus/rubber tree clade or that the transfer occurred after this clade split from the other species.

A phylogenetic tree constructed using seven species and 21 mitochondrial genes showed that rubber tree is most closely related to Ricinus (Figure 2). The number and type of mitochondrial genes can vary widely across species with gene loss and transfer to the nucleus occurring commonly [47]. Among the 7 species used we observed 26 different gene loss events (Figure 2). Interestingly, there were five events where genes that had previously been lost to a clade were regained by a species, two of these events were observed in Ricinus communis which regained rps 11 and trnD-GUC (as previously reported [48]). Rubber tree also regained trnD-GUC suggesting the event took place before the split from Ricinus communis. In each of these cases the regained gene was lost quite far back in the clade making it unlikely to be an error in the phylogenetic tree construction. It is interesting to note that rubber tree also gained a chloroplast copy of trnD-GUC (in addition to the mitochondrial copy mentioned above) suggesting that this tRNA might play an important role in the rubber tree mitochondria. 


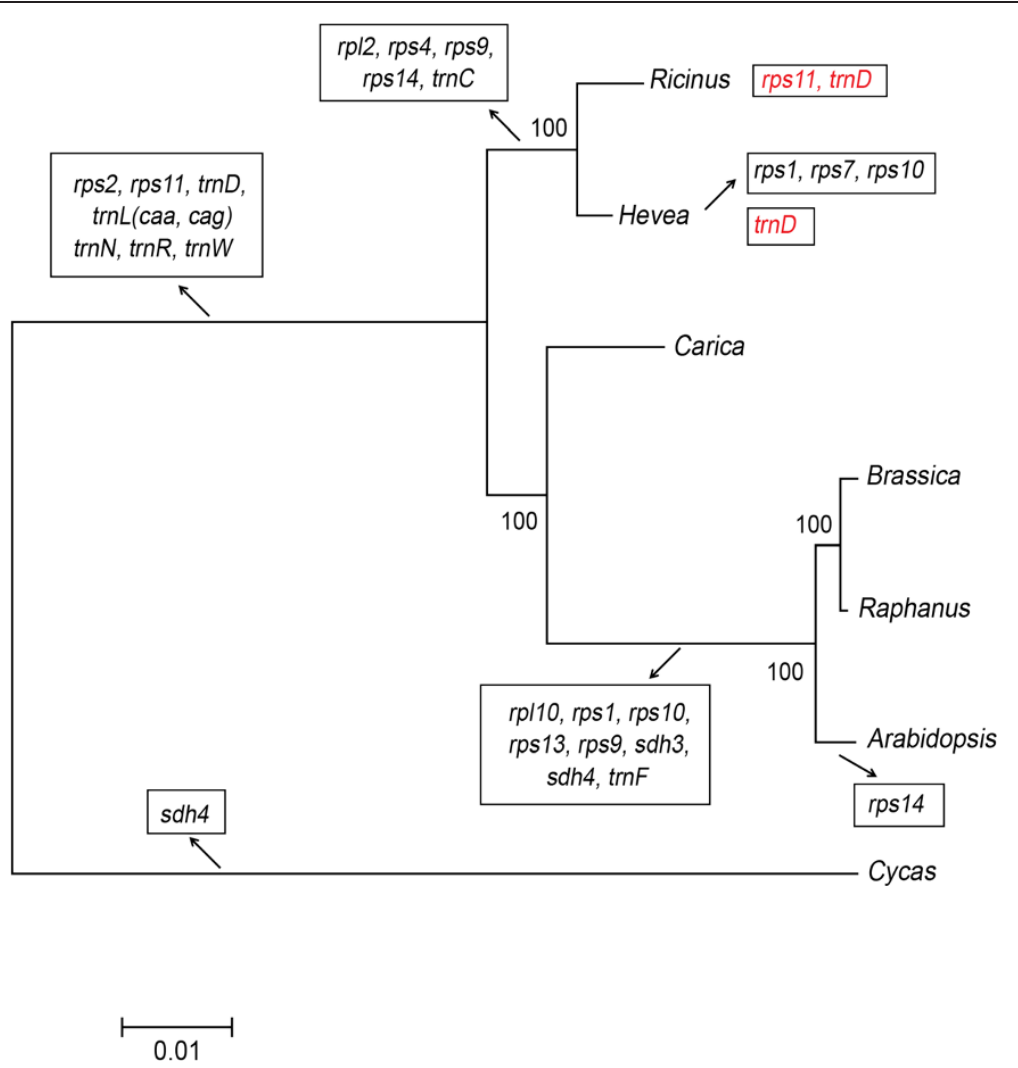

Figure 2 Phylogenetic tree of seven mitochondrial genomes in plants. Mitochondrial-like tRNA genes and protein-coding genes eliminated during evolution are presented in black boxes and genes that appear to have regained are presented in red boxes.

\section{RNA editing}

We identified cases of RNA editing by mapping the RNA-seq data to the assembled mitochondrial genome. This identified 224 cases among the six samples where the RNA-seq base was a thymine while the genomic base was a cytosine (see Additional file 4). Out of these sites 184 were also predicted to be RNA editing sites based on information from other species and 199 changed an amino acid. The most common amino acid changes were S to L with 52 events, P to L with 42 events and S to F with 29 events. RNA-editing was compared across 29 species, where data was available, and found to be highly conserved across all species (see Additional file 4). We found 8 cases where a $\mathrm{C}$ was edited to a $\mathrm{U}$ in rubber tree, in genes atp4, $\operatorname{cox} 1$, cox2, matR, nad1, nad2 and nad7, but remained an unedited $C$ in all other species (see Additional file 4). There was a single case, in cytochrome c biogenesis factor $C$ (ccmFC), where RNA-editing was required to produce a stop codon, this RNA-editing site was highly conserved among many species. The most heavily edited gene was cytochrome c oxidase subunit 2 (cox2) with 15 RNAediting events in $783 \mathrm{bp}$ of sequence.

Two cases were found where BPM 24 showed a lack of RNA-editing at a location where all the other rubber tree samples showed either RNA-editing or a variant, one was in succinate dehydrogenase subunit 3 (sdh3) and the other was in maturase- $R$ (matR). The $s d h 3$ RNAediting event did not change an amino acid and was not found in any other species so is unlikely to have a significant effect. The RNA-editing event in matR changes a hystidine residue (positively charged) to a tyrosine residue (hydrophobic with a negative dipole) which may be required for correct protein folding, but is not in a functional motif. The RNA-editing in mat $R$ was observed in four other species while six other species showed a $T$ variant. There were only two cases where a species with RNAediting information had the same base (C) as BPM 24 at this locus, however, this could represent incomplete information rather than a lack of RNA-editing. Mitochondrial encoded maturases have been found to be required for the proper splicing of some group II introns in Arabidopsis with mutations resulting in retarded growth and developmental phenotypes $[49,50]$. However, the specific function of matR remains unknown so whether this lack of RNA-editing plays a role in the CMS phenotype or not is unclear.

\section{Male sterility}

Since it is known that BPM 24 male sterility is mitochondrially inherited there must be a mitochondrial 
change that causes CMS [21]. With this in mind we compared contigs from the published rubber tree genome, variety RRIM 600 [19], that were identified as mitochondrial sequence against the BPM 24 mitochondrial contigs and scaffold assembly. This identified 11 contigs from the published genome that blast to the BPM 24 mitochondrial genome in a disjointed manner (Table 3 ) indicating a rearrangement in BPM 24 compared to the published rubber tree sequence. Five of these potential rearrangement sites that were within $1 \mathrm{~kb}$ of a gene were checked by PCR in six varieties of rubber tree. Two sites were found to exist in both the arrangement represented by the published genome and the arrangement represented by our assembly in all varieties, confirming the variation in mitochondrial subcircles identified in the scaffold graph. Three of these regions showed variation amongst the six varieties tested (see Additional file 2). One region was present as the published rubber tree (RRIM 600) arrangement in varieties BPM 24, RRII 105 and RRIM 600 but not in RRIC 110, RRIT 251 or PB 235, however all varieties had the BPM 24 arrangement for this region. Two rearrangements were unique to BPM 24 and in both cases were close to or within coding sequence making them good candidates for the cause of CMS in BPM 24.

The first rearrangement unique to BPM 24 was identified by the 1096 bp published RRIM 600 contig AJJZ010142287.1. The first 612 bp of this contig maps to 338444-339054 bp in the BPM 24 master circle and the last $585 \mathrm{bp}$ of the contig maps to $854280-854864$ bp in the master circle (Table 3). In the master circle the break point sections share a $101 \mathrm{bp}$ repeat sequence with 1 mismatch between the two sequences which may be the footprint

Table 3 Blast result of published contigs (RRIM 600) vs BPM 24 master circle showing 11 rearranged contigs

\begin{tabular}{|c|c|c|c|c|c|c|c|}
\hline Query id ${ }^{+}$ & $\%$ identity & Align length & q. start ${ }^{*}$ & q. end ${ }^{*}$ & 24 start $^{ \pm}$ & 24 end $^{ \pm}$ & e-value \\
\hline \multirow[t]{2}{*}{ AJJZO11005169.1 } & 85.93 & 135 & 549 & 683 & 338566 & 338700 & $7 e-27$ \\
\hline & 96.74 & 276 & 937 & 1211 & 854221 & 854495 & $4 e-130$ \\
\hline \multirow[t]{2}{*}{ AJJZ011005166.1 } & 98.79 & 1077 & 241 & 1317 & 21535 & 20459 & 0 \\
\hline & 96 & 200 & 1 & 198 & 1017254 & 1017055 & $4 e-87$ \\
\hline \multirow[t]{3}{*}{ AJJZ010488272.1 } & 100 & 144 & 182 & 325 & 115093 & 115236 & $3 e-78$ \\
\hline & 96.76 & 185 & 51 & 235 & 159007 & 159191 & $2 e-88$ \\
\hline & 100 & 117 & 1 & 117 & 221602 & 221486 & $4 e-62$ \\
\hline \multirow[t]{2}{*}{ AJJZ010386739.1 } & 98.62 & 217 & 186 & 401 & 179706 & 179922 & $4 e-112$ \\
\hline & 98.3 & 176 & 1 & 176 & 1031613 & 1031788 & $5 e-90$ \\
\hline \multirow[t]{2}{*}{ AJJZ010369193.1 } & 99.35 & 308 & 1 & 308 & 423994 & 424301 & $4 e-171$ \\
\hline & 100 & 203 & 306 & 508 & 663278 & 663076 & $3 e-113$ \\
\hline \multirow[t]{3}{*}{ AJJZ010233339.1 } & 94.44 & 162 & 567 & 728 & 202461 & 202622 & $1 e-66$ \\
\hline & 82.95 & 88 & 415 & 502 & 741897 & 741984 & $3 e-08$ \\
\hline & 86.92 & 107 & 414 & 520 & 882085 & 882190 & $1 \mathrm{e}-19$ \\
\hline \multirow[t]{4}{*}{ AJJZ010228768.1 } & 92.62 & 149 & 2483 & 2631 & 15228 & 15376 & $7 e-54$ \\
\hline & 84.71 & 327 & 2631 & 2934 & 15404 & 15728 & $6 e-67$ \\
\hline & 82.71 & 451 & 1622 & 2060 & 357491 & 357055 & $9 e-66$ \\
\hline & 87.14 & 770 & 831 & 1596 & 358263 & 357495 & 0 \\
\hline \multirow[t]{4}{*}{ AJJZ010174367.1 } & 91.99 & 1548 & 5871 & 7413 & 156744 & 158290 & 0 \\
\hline & 92.52 & 1096 & 9138 & 10223 & 529298 & 528203 & 0 \\
\hline & 89.38 & 885 & 10204 & 11068 & 894891 & 895774 & 0 \\
\hline & 94.33 & 141 & 11065 & 11203 & 895680 & 895820 & $3 e-40$ \\
\hline \multirow[t]{2}{*}{ AJJZ010143874.1 } & 99.97 & 7965 & 1 & 7965 & 38753 & 30789 & 0 \\
\hline & 100 & 1864 & 7733 & 9596 & 127434 & 125571 & 0 \\
\hline \multirow[t]{2}{*}{ AJJZ010142287.1 } & 99.18 & 612 & 1 & 612 & 338444 & 339054 & 0 \\
\hline & 100 & 585 & 512 & 1096 & 854280 & 854864 & 0 \\
\hline \multirow[t]{2}{*}{ AJJZ010039172.1 } & 98.4 & 187 & 80 & 266 & 17960 & 17774 & $6 e-97$ \\
\hline & 99.6 & 248 & 266 & 513 & 32045 & 32292 & $1 e-137$ \\
\hline
\end{tabular}

${ }^{+}$Italics indicates that the rearrangement or part of it has been confirmed by PCR.

* Start and end of query sequence alignment location.

${ }^{ \pm}$Start and end of master circle sequence alignment location. Bold indicates a gene is located within $1 \mathrm{~kb}$. 
of a homologous recombination (see Additional file 2). Interestingly, the 338444-339054 bp region has RNA-seq data supporting expression at this region but no gene is annotated in the assembly and BPM 24 has an extra $240 \mathrm{bp}$ of sequence that none of the other varieties share. This additional sequence was checked by PCR using primers flanking the break site and was confirmed to be present only in BPM 24 both in genomic DNA and cDNA (see Additional file 2). The sequence has an open reading frame encoding 51 amino acids, 33 of which are identical to the tail end of ATPase subunit 9 (atp9) plus 5 additional amino acids. A full copy of atp 9 is annotated as occurring at 760961-761254 bp and the RNA-seq data at this region is the same in all six rubber tree varieties. The rubber tree atp 9 has a transmembrane region near the amino-terminus and another near the carboxyl-terminus of the protein (Figure 3). The novel transcript incorporates the entire carboxyl-terminus transmembrane domain (Figure 3) which may allow it to compete with the full atp9 gene in the ATP synthase complex. It is likely that a recombination occurred in a subgenomic circle containing a copy of atp 9 in BPM 24 resulting in the novel transcript at this recombination site. The fact that the other rubber tree varieties also show expression at this location is likely a mapping artefact where RNA-seq reads from the normal gene are mapping to this section, this is supported by seven sequence variants between BPM 24 and the other rubber tree varieties in the RNA-seq reads that map to this section (see Additional file 2). This shows that the sequence identified at the $339 \mathrm{~kb}$ region is an additional transcript rather than a mutant form of atp 9 for BPM 24, similar to what has been identified in other CMS plants [51,52].

The second rearrangement was identified by the 11561 bp contig AJJZ010174367.1 from RRIM 600 that maps to four separate sections of the master circle (Table 3). The most interesting of these is Section 5871$7413 \mathrm{bp}$ of the published RRIM 600 contig that matches $156744-158290$ bp of the master circle, and similar to the first rearrangement, has a 29 bp repeat sequence near the break site and RNA-seq data supporting expression with $128 \mathrm{bp}$ of extra sequence unique to BPM 24. Using PCR primers that flanked the rearrangement site within the expressed section we found that the published contig sequence is present in all varieties and the rearranged sequence is found and expressed only in BPM 24 (see Additional file 2). The expressed sequence at this site matches ATPase subunit 1 (atp1) which is annotated at 156716-158245 bp on the master circle negative strand, placing one of the break points $45 \mathrm{bp}$ before the start codon of atp1 and the other 28 bp before the end of atp1. All varieties had RNA-seq data consistent
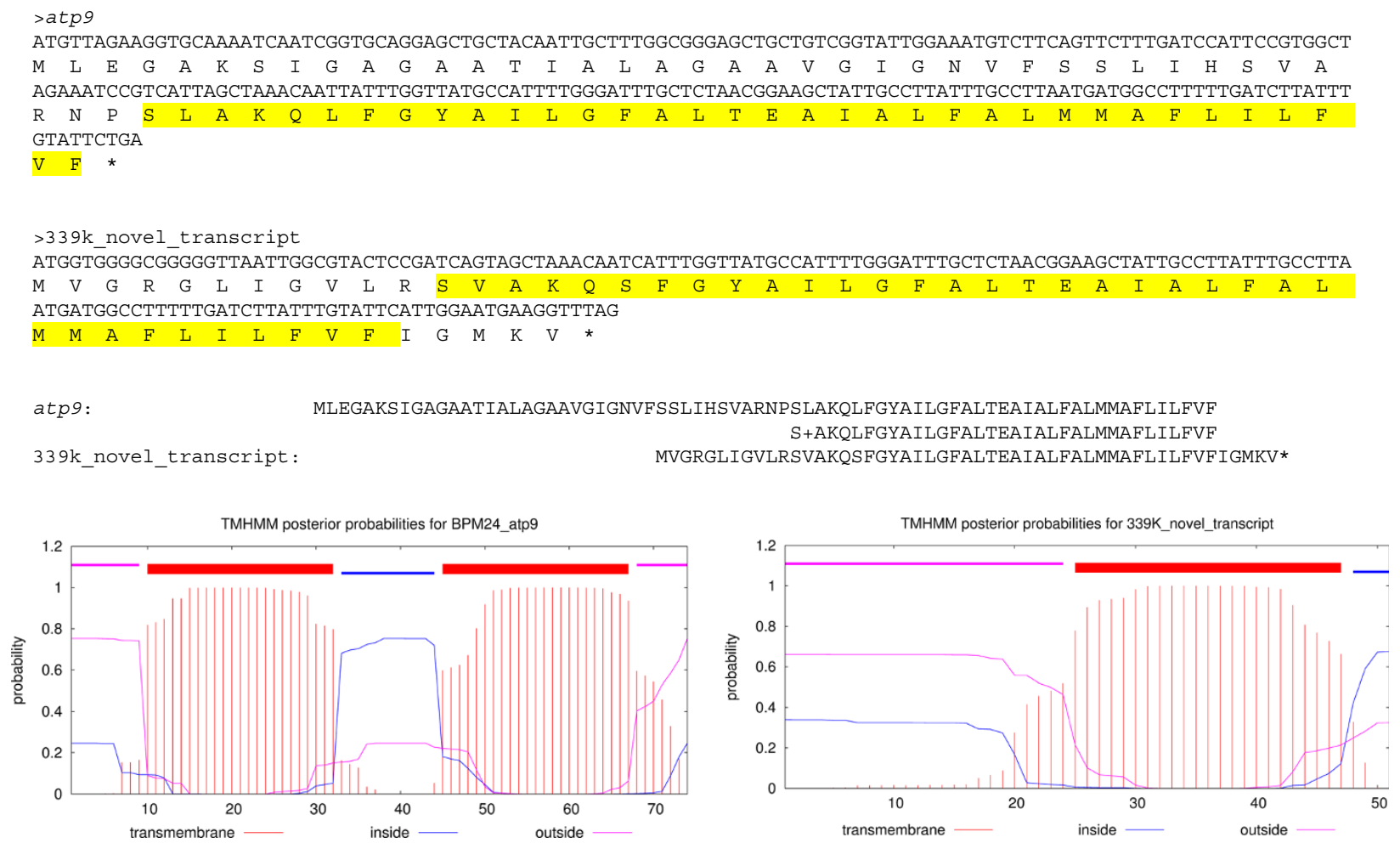

Figure 3 Comparison of the RNA and amino acid sequences of rubber tree apt9 with the novel transcript and the predicted trans-membrane structures of each. 
with a complete and functional copy of atp1 with the extra sequence in BPM 24 occurring after the stop codon suggesting that this variant is unlikely to affect the protein product.

A novel or fusion transcript is a common occurrence in CMS plants and often involves a portion of, or is near an ATP synthase subunit gene [53]. In total, nine cases of a novel transcript containing part of an ATP synthase gene have been found in CMS plants which are not found in control plants: atp1 in eggplant [54]; atp6 in maize [9], Brassica tournefortii [13], wheat [55] and chilli [56]; atp8 in sunflower [57]; atp9 in petunia [10], rapeseed [58] and sorghum [59]. In addition, disruptions to the ATP synthase complex, not featuring fusion transcripts, in plant mitochondria have been associated with CMS in chilli [60], Oryza rufipogon [61], Arabidopsis thaliana [62], wheat [63], maize [64] and tobacco [65]. Since the observed novel transcript in rubber tree is both a novel fustion transcript and includes a portion of an ATP synthase subunit, typical of a CMS causing change, it is highly likely to be the cause of CMS in rubber tree. While it may be difficult to imagine how disruption to such a fundamental function as energy production could result in male sterility but not affect any other cell type or developmental process, there is evidence that some cell types are more sensitive than others to perturbation of mitochondrial efficiency. A prime example of this is Leber's hereditary optic neuropathy in human where a mitochondrial mutation in an oxidative phosphorylation gene only affects retinal ganglion cells [66]. The most common finding in CMS plants is an additional transcript that contains part of an ATP synthase gene and is thus a gain of function change which explains how it can be specific to anthers. Anther development has a high energy demand and mitochondria undergo rapid expansion in copy number early during anther growth, increasing by as much as 40 fold per cell [67]. Anthers of CMS maize begin to breakdown shortly after this mitochondrial expansion suggesting a link between the two processes [67]. Indeed, cell death of sunflower CMS anthers has been associated with the release of mitochondrial cytochrome c oxidase into the cytosol [68], which is an activation signal for apoptosis-like cell death [69]. This particular form of sunflower CMS is caused by a novel transcript with atp8-like sequence and has been shown to have reduced ATP hydrolysis function [57]. Thus novel transcripts that encode part of an ATP synthase gene, such as the one identified in BPM 24, cause CMS, at least in some cases, by slightly reducing the ATP synthase complex activity to a point where mitochondria cannot generate sufficient energy for the highly energy reliant anthers resulting in mitochondria mediated apoptosislike cell death.

\section{Conclusion}

We have reconstructed the mitochondrial sequence of rubber tree clone BPM 24 and identified coding sequences and repeat elements. We then used the published contigs from RRIM 600 to identify rearrangements in BPM 24 that result in fusion transcripts for $a t p 1$ and $a t p 9$, with the atp9 fusion transcript likely reducing the efficiency of ATP production and resulting in cytoplasmic male sterility. Since BPM 24 is the offspring of the variety GT 1, we have indirectly identified the cause of CMS in GT 1 also. The exhaustive nature of this search approach rules out any other cause for the observed CMS in BPM 24 rubber tree and corroborates findings by other groups, often using less exhaustive search approaches, that novel fusion transcripts of ATP synthase genes can cause CMS.

\section{Availability of supporting data}

Rubber tree mitochondrial genome master circle: DDBJ: AP014526.

Rubber tree mitochondrial genome raw reads: DDBJ: DRA001347.

\section{Additional files}

Additional file 1: Primers and products showing rearrangement events and novel transcripts in the CMS rubber tree variety BPM 24. Additional file 2: Scaffold graph, primers and primer products used to confirm the scaffold order in the rubber tree master circle genome.

Additional file 3: Mapping results of the Illumina genomic data against the rubber tree master circle genome.

Additional file 4: Table of RNA editing events in the rubber tree RNA-seq data and comparison of RNA editing events to RNA editing event information from genbank.

Competing interests

The authors declare that they have no competing interests.

\section{Authors' contributions}

$\mathrm{KT}, \mathrm{STr}$ and STa conceived the study. JRS, PA, CS and PU performed the data analysis. DS, TY and SP performed the lab work. JRS and STa drafted the manuscript. All authors read and approved the final manuscript.

\section{Acknowledgements}

Samples and funding for this work were supplied by the Rubber Research Institute of Thailand (RRIT)

\section{Author details}

${ }^{1}$ National Center for Genetic Engineering and Biotechnology, 113 Thailand Science Park, Paholyothin Road, Khlong Nueng, Khlong Luang, Pathumthani 12120, Thailand. ${ }^{2}$ Rubber Research Institute of Thailand (RRIT), Department of Agriculture, Ministry of Agriculture and Cooperatives, 50 Phaholyothin Road, Chatuchack, Bangkok 10900, Thailand.

Received: 20 December 2013 Accepted: 7 February 2014 Published: 10 February 2014

\section{References}

1. McBride HM, Neuspiel M, Wasiak S: Mitochondria: more than just a powerhouse. Curr Biol 2006, 16:R551-R560. 
2. Unseld M, Marienfeld JR, Brandt $P$, Brennicke A: The mitochondrial genome of Arabidopsis thaliana contains 57 genes in 366,924 nucleotides. Nat Genet 1997, 15:57-61.

3. Palmer JD, Herbon LA: Unicircular structure of the Brassica hirta mitochondrial genome. Curr Genet 1987, 11:565-570

4. Rodríguez-Moreno L, González VM, Benjak A, Martí MC, Puigdomènech P, Aranda MA, Garcia-Mas J: Determination of the melon chloroplast and mitochondrial genome sequences reveals that the largest reported mitochondrial genome in plants contains a significant amount of DNA having a nuclear origin. BMC Genomics 2011, 12:424

5. Turmel M, Otis C, Lemieux C: The mitochondrial genome of Chara vulgaris: insights into the mitochondrial DNA architecture of the last common ancestor of green algae and land plants. Plant Cell 2003, 15:1888-1903.

6. Bullerwell CE, Gray MW: Evolution of the mitochondrial genome: protist connections to animals, fungi and plants. Curr Opin Microbiol 2004, 7:528-534.

7. Chang S, Yang T, Du T, Huang Y, Chen J, Yan J, He J, Guan R: Mitochondrial genome sequencing helps show the evolutionary mechanism of mitochondrial genome formation in Brassica. BMC Genomics 2011, 12:497.

8. Allen JO, Fauron CM, Minx P, Roark L, Oddiraju S, Lin GN, Meyer L, Sun H, Kim K, Wang C, Du F, Xu D, Gibson M, Cifrese J, Clifton SW, Newton KJ: Comparisons among two fertile and three male-sterile mitochondrial genomes of maize. Genetics 2007, 177:1173-1192.

9. Dewey RE, Levings CS 3rd, Timothy DH: Novel recombinations in the maize mitochondrial genome produce a unique transcriptional unit in the Texas male-sterile cytoplasm. Cell 1986, 44:439-449.

10. Young EG, Hanson MR: A fused mitochondrial gene associated with cytoplasmic male sterility is developmentally regulated. Cell 1987, 50:41-49.

11. Wang Z, Zou Y, Li X, Zhang Q, Chen L, Wu H, Su D, Chen Y, Guo J, Luo D, Long Y, Zhong Y, Liu Y-G: Cytoplasmic male sterility of rice with boro II cytoplasm is caused by a cytotoxic peptide and is restored by Two related PPR motif genes via distinct modes of mRNA silencing. Plant Cell Online 2006, 18:676-687.

12. Laver HK, Reynolds SJ, Moneger F, Leaver CJ: Mitochondrial genome organization and expression associated with cytoplasmic male sterility in sunflower (Helianthus annuus). Plant J Cell Mol Biol 1991, 1:185-193.

13. Landgren M, Zetterstrand M, Sundberg E, Glimelius K: Alloplasmic male-sterile Brassica lines containing $B$. tournefortii mitochondria express an ORF $3^{\prime}$ of the atp6 gene and a 32 kDa protein. off. Plant Mol Biol 1996, 32:879-890.

14. Gallagher LJ, Betz SK, Chase CD: Mitochondrial RNA editing truncates a chimeric open reading frame associated with $\mathrm{S}$ male-sterility in maize. Curr Genet 2002, 42:179-184.

15. Dill CL, Wise RP, Schnable PS: Rf8 and Rf* mediate unique T-urf13transcript accumulation, revealing a conserved motif associated with RNA processing and restoration of pollen fertility in T-cytoplasm maize. Genetics 1997, 147:1367-1379.

16. Rivarola M, Foster JT, Chan AP, Williams AL, Rice DW, Liu X, Melake-Berhan A, Huot Creasy H, Puiu D, Rosovitz MJ, Khouri HM, Beckstrom-Sternberg SM, Allan GJ, Keim P, Ravel J, Rabinowicz PD: Castor bean organelle genome sequencing and worldwide genetic diversity analysis. PLoS One 2011, 6:e21743.

17. Iorizzo M, Senalik D, Szklarczyk M, Grzebelus D, Spooner D, Simon P: De novo assembly of the carrot mitochondrial genome using next generation sequencing of whole genomic DNA provides first evidence of DNA transfer into an angiosperm plastid genome. BMC Plant Biol 2012, $12: 61$

18. Fang $Y$, Wu $H$, Zhang $T$, Yang $M$, Yin $Y$, Pan $L, Y u X$, Zhang $X$, Hu S, Al-Mssallem IS, Yu J: A complete sequence and transcriptomic analyses of date palm (Phoenix dactylifera L.) mitochondrial genome. PLoS One 2012, 7:e37164.

19. Rahman AYA, Usharraj AO, Misra BB, Thottathil GP, Jayasekaran K, Feng $Y$, Hou S, Ong SY, Ng FL, Lee LS, Tan HS, Sakaff MKLM, Teh BS, Khoo BF, Badai SS, Aziz NA, Yuryev A, Knudsen B, Dionne-Laporte A, Mchunu NP, Yu Q, Langston BJ, Freitas TAK, Young AG, Chen R, Wang L, Najimudin N, Saito JA, Alam M: Draft genome sequence of the rubber tree Hevea brasiliensis. BMC Genomics 2013, 14:75.

20. Tangphatsornruang S, Uthaipaisanwong P, Sangsrakru D, Chanprasert J, Yoocha T, Jomchai N, Tragoonrung S: Characterization of the complete chloroplast genome of Hevea brasiliensis reveals genome rearrangement, RNA editing sites and phylogenetic relationships. Gene 2011, 475:104-112.

21. Priyadarshan PM, Clément-Demange A: Breeding Hevea rubber: formal and molecular genetics. Adv Genet 2004, 52:51-115.

22. Triwitayakorn $K$, Chatkulkawin P, Kanjanawattanawong S, Sraphet S, Yoocha T, Sangsrakru D, Chanprasert J, Ngamphiw C, Jomchai N, Therawattanasuk K, Tangphatsornruang S: Transcriptome sequencing of Hevea brasiliensis for development of microsatellite markers and construction of a genetic linkage map. DNA Res Int J Rapid Publ Rep Genes Genomes 2011, 18:471-482.

23. Boetzer M, Henkel CV, Jansen HJ, Butler D, Pirovano W: Scaffolding pre-assembled contigs using SSPACE. Bioinforma Oxf Engl 2011, 27:578-579.

24. Darling ACE, Mau B, Blattner FR, Perna NT: Mauve: multiple alignment of conserved genomic sequence with rearrangements. Genome Res 2004, 14:1394-1403.

25. Lohse M, Bolger AM, Nagel A, Fernie AR, Lunn JE, Stitt M, Usadel B: RobiNA: a user-friendly, integrated software solution for RNA-Seq-based transcriptomics. Nucleic Acids Res 2012, 40(Web Server issue):W622-W627.

26. Kim D, Pertea G, Trapnell C, Pimentel H, Kelley R, Salzberg SL: TopHat2: accurate alignment of transcriptomes in the presence of insertions, deletions and gene fusions. Genome Bio/ 2013, 14:R36.

27. Langmead B, Trapnell C, Pop M, Salzberg SL: Ultrafast and memory-efficient alignment of short DNA sequences to the human genome. Genome Biol 2009, 10:R25.

28. Schattner P, Brooks AN, Lowe TM: The tRNAscan-SE, snoscan and snoGPS web servers for the detection of tRNAs and snoRNAs. Nucleic Acids Res 2005, 33(Web Server issue):W686-W689.

29. Alverson AJ, Wei X, Rice DW, Stern DB, Barry K, Palmer JD: Insights into the evolution of mitochondrial genome size from complete sequences of Citrullus lanatus and Cucurbita pepo (Cucurbitaceae). Mol Biol Evol 2010, 27:1436-1448

30. Koboldt DC, Chen K, Wylie T, Larson DE, McLellan MD, Mardis ER, Weinstock GM, Wilson RK, Ding L: VarScan: variant detection in massively parallel sequencing of individual and pooled samples. Bioinforma Oxf Engl 2009, 25:2283-2285.

31. Mower JP: The PREP suite: predictive RNA editors for plant mitochondrial genes, chloroplast genes and user-defined alignments. Nucleic Acids Res 2009, 37(Web Server issue):W253-W259.

32. Krogh A, Larsson B, von Heijne G, Sonnhammer EL: Predicting transmembrane protein topology with a hidden Markov model: application to complete genomes. J Mol Biol 2001, 305:567-580.

33. Tamura K, Peterson D, Peterson N, Stecher G, Nei M, Kumar S: MEGA5: molecular evolutionary genetics analysis using maximum likelihood, evolutionary distance, and maximum parsimony methods. Mol Biol Evol 2011, 28:2731-2739.

34. Mackenzie Ml: Higher plant mitochondria. Plant Cell 1999, 11:571-586.

35. Manchekar M, Scissum-Gunn K, Song D, Khazi F, McLean SL, Nielsen BL: DNA recombination activity in soybean mitochondria. J Mol Biol 2006, 356:288-299.

36. Alverson AJ, Rice DW, Dickinson S, Barry K, Palmer JD: Origins and recombination of the bacterial-sized multichromosomal mitochondrial genome of cucumber. Plant Cell 2011, 23:2499-2513.

37. Chen J, Guan R, Chang S, Du T, Zhang H, Xing H: Substoichiometrically different mitotypes coexist in mitochondrial genomes of Brassica napus L. PLoS One 2011, 6:e17662

38. Kazakoff SH, Imelfort M, Edwards D, Koehorst J, Biswas B, Batley J, Scott PT, Gresshoff PM: Capturing the biofuel wellhead and powerhouse: the chloroplast and mitochondrial genomes of the leguminous feedstock tree Pongamia pinnata. PLoS One 2012, 7:e51687.

39. Mower JP, Case AL, Floro ER, Willis JH: Evidence against equimolarity of large repeat arrangements and a predominant master circle structure of the mitochondrial genome from a monkeyflower (Mimulus guttatus) lineage with cryptic CMS. Genome Biol Evol 2012, 4:670-686.

40. Sloan DB, Alverson AJ, Chuckalovcak JP, Wu M, McCauley DE, Palmer JD, Taylor DR: Rapid evolution of enormous, multichromosomal genomes in flowering plant mitochondria with exceptionally high mutation rates. PLOS Biol 2012, 10:e1001241.

41. Tanaka Y, Tsuda M, Yasumoto $K$, Yamagishi H, Terachi T: A complete mitochondrial genome sequence of Ogura-type male-sterile cytoplasm and its comparative analysis with that of normal cytoplasm in radish (Raphanus sativus L.). BMC Genomics 2012, 13:352. 
42. Zhang T, Hu S, Zhang G, Pan L, Zhang X, Al-Mssallem IS, Yu J: The organelle genomes of Hassawi rice (Oryza sativa L.) and its hybrid in saudi arabia: genome variation, rearrangement, and origins. PLoS One 2012, 7:e42041.

43. McKinney EA, Oliveira MT: Replicating animal mitochondrial DNA. Genet Mol Biol 2013, 36:308-315

44. Woloszynska M: Heteroplasmy and stoichiometric complexity of plant mitochondrial genomes-though this be madness, yet there's method in't. J Exp Bot 2010, 61:657-671.

45. Bonen L: Cis- and trans-splicing of group II introns in plant mitochondria. Mitochondrion 2008, 8:26-34.

46. Wang D, Wu Y-W, Shih AC-C, Wu C-S, Wang Y-N, Chaw S-M: Transfer of chloroplast genomic DNA to mitochondrial genome occurred at least 300 MYA. Mol Biol Evol 2007, 24:2040-2048.

47. Adams KL, Palmer JD: Evolution of mitochondrial gene content: gene loss and transfer to the nucleus. Mol Phylogenet Evol 2003, 29:380-395.

48. Chang S, Wang Y, Lu J, Gai J, Li J, Chu P, Guan R, Zhao T: The mitochondrial genome of soybean reveals complex genome structures and gene evolution at intercellular and phylogenetic levels. PLoS One 2013, 8:e56502.

49. Keren I, Bezawork-Geleta A, Kolton M, Maayan I, Belausov E, Levy M, Mett A, Gidoni D, Shaya F, Ostersetzer-Biran O: AtnMat2, a nuclear-encoded maturase required for splicing of group-II introns in Arabidopsis mitochondria. RNA N Y N 2009, 15:2299-2311.

50. Keren I, Tal L, des Francs-Small CC, Araújo WL, Shevtsov S, Shaya F, Fernie AR, Small I, Ostersetzer-Biran O: nMAT1, a nuclear-encoded maturase involved in the trans-splicing of nad1 intron 1, is essential for mitochondrial complex I assembly and function. Plant J Cell Mol Biol 2012, 71:413-426.

51. Kiang AS, Kavanagh TA: Cytoplasmic male sterility (CMS) in Lolium perenne L. 2. The mitochondrial genome of a CMS line is rearranged and contains a chimaeric atp 9 gene. TAG Theor App/ Genet Theor Angew Genet 1996, 92:308-315.

52. Folkerts $\mathrm{O}$, Hanson MR: The male sterility-associated pcf gene and the normal atp9-1 gene in Petunia are located on different mitochondrial DNA molecules. Genetics 1991, 129:885-895.

53. Carlsson J, Leino M, Sohlberg J, Sundström JF, Glimelius K: Mitochondrial regulation of flower development. Mitochondrion 2008, 8:74-86.

54. Yoshimi M, Kitamura Y, Isshiki S, Saito T, Yasumoto K, Terachi T, Yamagishi H: Variations in the structure and transcription of the mitochondrial atp and cox genes in wild Solanum species that induce male sterility in eggplant (S. melongena). TAG Theor Appl Genet Theor Angew Genet 2013, 126:1851-1859.

55. Wang J, Wang $X, X u H$, Tang $H$, Zhang G, Liu Y-G: Structural and expressional variation analyses of mitochondrial genomes reveal candidate transcripts for the $\mathrm{S}(\mathrm{V})$ cytoplasmic male sterility in wheat (Triticum aestivum L.). J Genet Genomics Yi Chuan Xue Bao 2013, 40:437-439.

56. Kim DH, Kang JG, Kim B-D: Isolation and characterization of the cytoplasmic male sterility-associated orf456 gene of chili pepper (Capsicum annuum L.). Plant Mol Biol 2007, 63:519-532.

57. Sabar M, Gagliardi D, Balk J, Leaver CJ: ORFB is a subunit of F1F(O)-ATP synthase: insight into the basis of cytoplasmic male sterility in sunflower. EMBO Rep 2003, 4:381-386

58. Dieterich J-H, Braun H-P, Schmitz UK: Alloplasmic male sterility in Brassica napus (CMS "Tournefortii-Stiewe") is associated with a special gene arrangement around a novel atp9 gene. Mol Genet Genomics MGG 2003, 269:723-731.

59. Tang HV, Pring DR, Shaw LC, Salazar RA, Muza FR, Yan B, Schertz KF: Transcript processing internal to a mitochondrial open reading frame is correlated with fertility restoration in male-sterile sorghum. Plant J Cell Mol Biol 1996, 10:123-133.

60. Li J, Pandeya D, Jo YD, Liu WY, Kang B-C: Reduced activity of ATP synthase in mitochondria causes cytoplasmic male sterility in chili pepper. Planta 2013, 237:1097-1109.

61. Igarashi K, Kazama T, Motomura K, Toriyama K: Whole genomic sequencing of RT98 mitochondria derived from Oryza rufipogon and northern blot analysis to uncover a cytoplasmic male sterility-associated gene. Plant Cell Physiol 2013, 54:237-243.

62. Geisler DA, Päpke C, Obata T, Nunes-Nesi A, Matthes A, Schneitz K, Maximova E, Araújo WL, Fernie AR, Persson S: Downregulation of the $\delta$-subunit reduces mitochondrial ATP synthase levels, alters respiration, and restricts growth and gametophyte development in Arabidopsis. Plant Cell 2012, 24:2792-2811.
63. Xu P, Yang Y, Zhang Z, Chen W, Zhang C, Zhang L, Zou S, Ma Z: Expression of the nuclear gene $\operatorname{TaF}(\mathrm{A}) \mathrm{d}$ is under mitochondrial retrograde regulation in anthers of male sterile wheat plants with timopheevii cytoplasm. J Exp Bot 2008, 59:1375-1381.

64. Wen L, Ruesch KL, Ortega VM, Kamps TL, Gabay-Laughnan S, Chase CD: A nuclear restorer-of-fertility mutation disrupts accumulation of mitochondrial ATP synthase subunit alpha in developing pollen of $S$ male-sterile maize. Genetics 2003, 165:771-779.

65. Bergman P, Edqvist J, Farbos I, Glimelius K: Male-sterile tobacco displays abnormal mitochondrial atp1 transcript accumulation and reduced floral ATP/ADP ratio. Plant Mol Biol 2000, 42:531-544.

66. Rezvani Z, Didari E, Arastehkani A, Ghodsinejad V, Aryani O, Kamalidehghan $\mathrm{B}$, Houshmand M: Fifteen novel mutations in the mitochondrial NADH dehydrogenase subunit 1, 2, 3, 4, 4L, 5 and 6 genes from Iranian patients with Leber's hereditary optic neuropathy (LHON). Mol Biol Rep 2013, 40:6837-6841.

67. Lee S-LJ, Warmke H: Organelle size and number in fertile and T-cytoplasmic male-sterile corn. Am J Bot 1979, 66:141-148.

68. Balk J, Leaver CJ: The PET1-CMS mitochondrial mutation in sunflower is associated with premature programmed cell death and cytochrome c release. Plant Cell 2001, 13:1803-1818.

69. Reape TJ, McCabe PF: Apoptotic-like programmed cell death in plants. New Phytol 2008, 180:13-26.

doi:10.1186/1471-2229-14-45

Cite this article as: Shearman et al:: Assembly and analysis of a male sterile rubber tree mitochondrial genome reveals DNA rearrangement events and a novel transcript. BMC Plant Biology 2014 14:45.

\section{Submit your next manuscript to BioMed Central and take full advantage of:}

- Convenient online submission

- Thorough peer review

- No space constraints or color figure charges

- Immediate publication on acceptance

- Inclusion in PubMed, CAS, Scopus and Google Scholar

- Research which is freely available for redistribution 